\title{
Combined Effect of Marble Waste as Powder and Aggregate Form on the Proprieties of the Mortar
}

\author{
Mekki Maza $^{1}{ }^{*}$, Nadia Tebbal$^{2}$, Salim Zitouni ${ }^{1}$, Zine El Abidine Rahmouni ${ }^{1}$ \\ ${ }^{1}$ Laboratory for Geo-Materials Development, Civil Engineering Department, Faculty of Technology, Msila University, M'sila \\ 28000, Algeria \\ ${ }^{2}$ Institute of Urban Techniques and Management, Msila University, M'sila 28000, Algeria
}

Corresponding Author Email: nadia.tebbal@univ-msila.dz

https://doi.org/10.18280/acsm.450605

Received: 12 December 2021

Accepted: 26 December 2021

\section{Keywords:}

recycling, environment, marble waste, sand, mechanical strengths, mortar

\begin{abstract}
Recycling and recovery of waste are now considered as a solution for the future to protect the environment. The marble processing workshops on the other hand, generate a large amount of waste in the form of powder and small parts. Due to these facts, the aim of this study is to valorize marble waste in the form of powder and crushed aggregates (sand) as additions in cementitious matrix building materials. The characterization of the materials used to formulate mortars based on natural dune sand with marble powder and mortars based on mixed sand (dunes sand and crushed sand) and marble powder was measure. In this sense, several series have been studied, varying the addition rate of the marble powder in order to reduce the porosity of the cement matrix, using crushed marble sand to increase the granular cohesion and using of a reducing water admixture (MEDAPLAST SP40) for more performance mortars. Very appreciable results were observed for a dosage of $15 \%$ of marble powder and for the combination of $15 \%$ of marble powder with $20 \%$ of crushed marble sand. This research recommends recycling $35 \%$ of marble waste in the cement matrix that contribute effectively to the preservation of the environment.
\end{abstract}

\section{INTRODUCTION}

Faced with the growing need for material resources and the requirements of environmental preservation and a vision of sustainable development, it has become necessary and relevant to explore and study all possibilities for recycling and recovery of waste and by-products, particularly in the field of civil engineering [1-3].

Waste is a real problem, inevitable for all biological life and all industrial activity [4]. Recycling has two beneficial ecological consequences, reducing the volume of waste and preserving natural resources [5]. The valuation of waste and industrial by-products in civil engineering must therefore be analyzed in terms of economy, ecology and behavior [6]. Developing countries, including Algeria, are lagging behind in the management of such wastes they are most often abandoned in wild dumps causing an impact on the environment. In the perspective of sustainable development, it is advisable to think about the recycling of industrial waste and rubble [7-9]. The use of waste for new products is an evolving global trend. Recycling materials allow for a more efficient life cycle and help protect the environment. In the field of construction, this trend has become more important because of the shortage of natural resources and the environmental problems caused by the storage of waste. Several types of residues, by-products and miscellaneous waste can be used depending on their operating profitability and their properties as aggregates. This situation has led to the search for new applications for these wastes; their use as additions and aggregates in concrete and mortar is an interesting alternative. Mineral powders are wastes that can be used in concrete as admixtures [10,11]. They can help improve the rheology of concrete and reduce the heat of hydration and the cost of production $[12,13]$. They also have ecological aspects because reducing the amount of cement reduces carbon dioxide emissions during concrete and mortar production [14]. It is known that using industrial waste in concrete or mortar as part of waste management is getting wider [15].

In literature there are studies on the effects of using mineral powders in concrete. However, most of them focus on mechanical and rheological properties $[12,16,17]$. It was found in many researches that such nanomaterials as: silica fume, fly ash or pozzolana can improve water tightness or reduce porosity of concrete by filling capillary pores [18-20]. Mineral powders probably can act in the same way.

In Algeria, large quantities of fine marble are produced each year. These marble fillers are generated as a byproduct when cutting marble. During the process of cutting and polishing, approximately $25 \%$ of marble waste is obtained in the form of fillers. This marble waste is roundly thrown in nature which represents a real threat to the ecosystem and biological components of the environment. Therefore, the use of marble fillers in the production of new materials will help protect the environment $[21,22]$. Recently, the use of marble powder as a replacement material has been studied and demonstrated that the presence of marble dust (MD) in the matrix enhances the early compressive strength of the mortar, and the strength of the mortar decreases with the increasing MD content [21, 23].

Currently the incorporation of mineral additions is an important technique in improving the properties of concrete 
and mortar such as fluidity, strength and durability. However, to take full benefit of these advantages and choose the best solution to optimize the formulation, it is necessary to know the characteristics of these new components (mineral additives) and their effects on the properties of concretes and mortars.

A literature review on the usage of marble powder in concrete or mortar was presented with the following paragraph.

Mansour et al. [24], used marble waste as mineral addition in polymer concrete incorporating alfa fibers. The results of flexural testing of unreinforced polymer concrete with different rates of charges (marble) showed that the concrete with $20 \%$ of marble is stronger and more rigid compared to other grades. Hence, a rate of $20 \%$ of marble powder is selected as the optimal value in the development of polymer concrete reinforced Alfa fibers.

The research of Ouassila et al. [25], consist in recovering a waste marble (thrown power exposed to the different meteorological phenomena) and add it, as sand in the composition of sand concrete. This research analyzed the evolution brought by the substitution of ordinary sand by marble waste sand, with $25 \%, 50 \%, 75 \%$ and $100 \%$ on the properties in the fresh state (density, workability and air content) and in the cured state (compressive strength, tensile strength, surface hardness and sound velocity). The result showed that the partial substitution modified the fresh and the hardened characteristics of the tested concretes, the durability parameters also improved.

Yamanel et al. [26], made a laboratory study to investigate utilization of waste marble as a replacement of cement on the properties of mortar. As a result of laboratory study, it is concluded that replacing marble powder with cement result with a favorable contribution to workability of fresh mortar, as well as resistance to elevated temperature. It also reduced drying shrinkage of mortar in comparison to reference mortar made without marble powder. However, it influenced water absorption, abrasion, and carbonation resistance of mortar, unfavorably. For short term curing duration, replacement of marble powder with cement reduced compressive strength insignificantly for $5 \%$ and $10 \%$ marble powder replacement, but, reduced it significantly for $15 \%$ and $20 \%$. However, at long term curing at 90 days, the difference between strength of reference mortar and marble containing mortar was diminished, particularly for mortar containing 5\% and $10 \%$ marble powder.

In the research of Kabeer and Vyas [27], he has been shown that marble powder confers high cohesiveness to the concrete mixtures and increases the compressive strength by $10 \%$ replacement of sand: this reduces the water in mix proportions by $20 \%$ and achieved good compressive strength by $60 \%$ replacement of sand by MD. Other study undertaken on the subject reported that replacement sand with marble powder by $10 \%, 20 \%, 30 \%, 40 \%, 50 \%$ and $90 \%$ by volume used in feasibility evaluation and it shows usage upto $40 \%$ marble powder in concrete is suitable [28].

The partial replacement of Marble dust in the mortar increases the compressive and flexural strength if the replacement of fine aggregate upto $25 \%$. The water absorption and sorptivity coefficient of the cement mortar cube with marble powder increases $40 \%$ with increase in the percentage of the marble dust.

Zhang et al. [29] have been blends and adds artificial marble waste powder to concrete, aiming to disclose the effects of the powder on the physical and mechanical properties of concrete. The analysis of this test results concluded that both blending and addition of artificial marble waste powder can improve the cohesiveness and bleeding of concrete. The blending is an effective way to increase the slump of concrete, while the addition suppresses the slump. This study proved and recommended to add $20 \%$ of artificial marble waste powder into concrete.

According to Belouadah studies [30, 31], They found at early age of curing, the values of the compressive strength and ultrasonic pulse velocity were quite small for all replacement levels, of cement with marble powder, between 15 and $30 \%$. Nevertheless, when the curing period was increased, the compressive strength and ultrasonic pulse velocity of all the samples went up as well.

This research aims to study the influence of the combined introduction of marble waste in the form of filler with percentages of $5,10,15$ and $20 \%$ of the weight of sand as an addition, in order to lower the porosity by partial replacement of sand dune with crushed marble sand $(0 / 3) \mathrm{mm}$ to improve the cohesion between sand grains and the incorporation as a water-reducing admixture (MEDAPLAST SP40), leading to the making of a mortar based on local materials characterized by better workability, mechanical strength, minimal porosity and acceptable durability.

\section{EXPERIMENTAL PROGRAM}

\subsection{Materials}

Cement: The Portland cement type NA 442 - CEM 152,5 R from Hammam Dalâa local factory was used in this experimental study. The used cement type has an absolute density, consistency and fineness values of $3.1 \mathrm{~g} / \mathrm{cm}^{3},(28 \pm$ 3) $\%$ and $4000-5400 \mathrm{~cm}^{2} / \mathrm{g}$, respectively. The physical properties, chemical composition and particle size of cement with laser analysis are shown in Table 1.

Dune Sand: The natural fine aggregate fraction used is sand dune with particles ranging from $0.08 \mathrm{~mm}$ to $5 \mathrm{~mm}$ in size, with a fineness modulus of 2.44 . The absolute density and porosity were $2.61 \mathrm{~g} / \mathrm{cm}^{3}$ and $42 \%$, respectively. The physical characteristics are summarized in Table 1.

This natural sand is taken from the region of Oued souf, (630 $\mathrm{km}$ east of Algiers). The sieve analysis is performed according to the European standard NF EN 933-1 [32]. The Mineralogical composition determined by X-ray diffraction shows that the crystalline mineral phases identified for the sand dune (Figure 1) is mainly composed more than $92.96 \%$ of quartz $\left(\mathrm{SiO}_{2}\right)$, calcite traces and anorthite $\left(\mathrm{CaSi}_{2} \mathrm{Al}_{2} \mathrm{O}_{8}\right)$. It has a small but evident band ranging from $20^{\circ}$ and $30^{\circ}$, indicating the presence of amorphous materials. Silicate and lime are predominant in terms of chemical composition that also indicates the presence of alumina, iron and magnesium in small quantities. The chemical composition is shown in Table 1 .

Marble Powder (MP): Marble powder is recovered from the processing workshops; the small pieces of marble (waste) undergo a slight crushing by hand and passed a $5 \mathrm{~mm}$ sieve. The mineralogical composition determined by X-ray diffraction shows that the dominant element in the marble powder is calcium carbonate $\mathrm{CaCO}_{3}$. The physical and chemical properties of $M P$ are shown in Table 1 and Figure 3.

Chemical admixture (superplasticizer and water reducing): In order to check the workability of the mortar it was used the superplasticizer reducer water manufactured by the company 
of Algeria Granitex marketed under the name high of MEDAPLAST SP 40. The manufacturer's recommendation of 0,6 to 2 , and $5 \%$ was taken in to accost the cement weight.
The percentage of the chemical admixture used was $1 \%$ by weight of cement for all mixes. The properties of the chemical admixture are represented in Table 1.

Table 1. The chemical, physical properties of cement, dune sand and marble powder

\begin{tabular}{|c|c|c|c|c|c|c|c|}
\hline \multicolumn{2}{|c|}{ Content (\%) } & \multicolumn{2}{|c|}{ Cement } & Dune sand & \multicolumn{3}{|c|}{ Marble powder } \\
\hline $\mathrm{SiO}_{2}$ & & \multicolumn{2}{|c|}{23.1} & 92.96 & \multicolumn{3}{|c|}{-} \\
\hline $\mathrm{Al}_{2} \mathrm{O}_{3}$ & & \multicolumn{2}{|c|}{6.2} & 2.21 & \multicolumn{3}{|c|}{0,09} \\
\hline Cao & & \multicolumn{2}{|c|}{67.8} & 2.039 & \multicolumn{3}{|c|}{55,78} \\
\hline $\mathrm{Fe}_{2} \mathrm{O}_{3}$ & & \multicolumn{2}{|c|}{0.28} & 0.79 & \multicolumn{3}{|c|}{0,01} \\
\hline $\mathrm{MgO}$ & & \multicolumn{2}{|c|}{0.83} & 0.02 & \multicolumn{3}{|c|}{0,47} \\
\hline $\mathrm{SO}_{3}$ & & \multicolumn{2}{|c|}{0.89} & 0.15 & \multicolumn{3}{|c|}{0,05} \\
\hline $\mathrm{K}_{2} \mathrm{O}$ & & \multicolumn{2}{|c|}{0.4} & 1.16 & \multicolumn{3}{|c|}{-} \\
\hline \multicolumn{2}{|l|}{$\mathrm{Na}_{2} \mathrm{O}$} & \multicolumn{2}{|c|}{0.05} & 0.34 & \multicolumn{3}{|c|}{-} \\
\hline \multicolumn{8}{|c|}{ Mineralogical analysis of marble powder (MP) } \\
\hline Elements & R.wp & Calcite & Dolomite & Quartz & Illite Chlorite & Kaolinite & $\mathrm{CO}_{2-\mathrm{XRD}}$ \\
\hline Content $(\%)$ & 6.19 & 98.96 & 0.64 & 0.14 & $0.05 \quad 0.06$ & 0.16 & 43.81 \\
\hline \multicolumn{8}{|c|}{$\begin{array}{l}\text { Physical properties of manufactured fine and fines aggregates } \\
\text { (Dune sand, crushed marble and powder marble) }\end{array}$} \\
\hline \multirow{2}{*}{\multicolumn{2}{|c|}{ Absolute density $(\mathrm{kg} / \mathrm{l})$}} & \multicolumn{3}{|c|}{$\begin{array}{l}\text { Sand Dune } \\
(0 / 5) \mathrm{mm}\end{array}$} & Crushed marble & \multicolumn{2}{|c|}{$\begin{array}{c}\text { Marble powder } \\
<80 \mu\end{array}$} \\
\hline & & \multicolumn{3}{|c|}{2.54} & 2.63 & \multicolumn{2}{|c|}{2.63} \\
\hline \multicolumn{2}{|c|}{ Bulk density (kg/l) } & \multicolumn{3}{|c|}{1.67} & 1.78 & \multicolumn{2}{|c|}{1.71} \\
\hline Porosity & & \multicolumn{3}{|c|}{34.13} & 32.38 & \multicolumn{2}{|c|}{38.04} \\
\hline Fineness $\mathrm{mc}$ & ulus & & 2.07 & & 2.98 & & - \\
\hline & Char & cteristics & of the chen & I admixture & (MEDAPLAST & SP 40) & \\
\hline Nature & & Color & $\mathrm{Ph}$ & Density & Chlorin & content & Dry extract \\
\hline Liquid & & Brown & 8.2 & $1.20 \pm 0.0$ & & & $40 \%$ \\
\hline
\end{tabular}

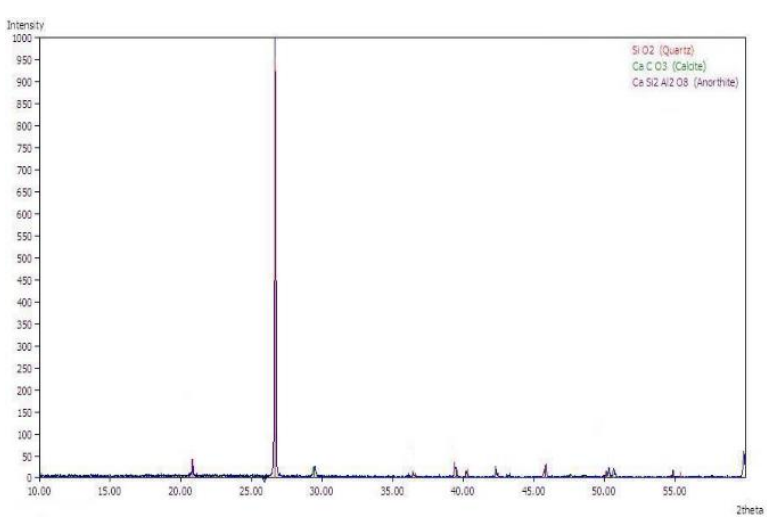

Figure 1. Diffractometer analysis X-ray of dune sand

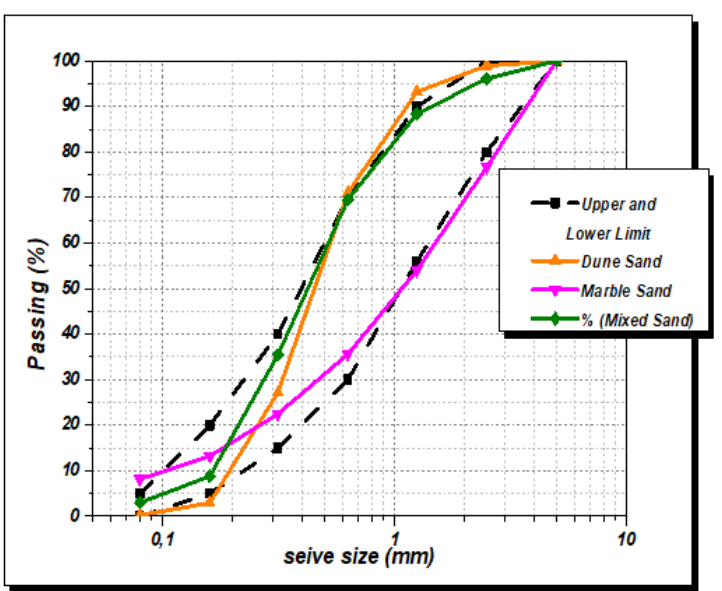

Figure 2. Particle size distribution curve of sands used

Mixing water: Water is an important ingredient of Mortar as it actually participates in the chemical reaction with cement. Since it helps to form the strength development. The quantity and quality of water is required to hand hydrates for very carefully. Potable tap water was used for mortar mixing all through the study and contains none harmful impurity.

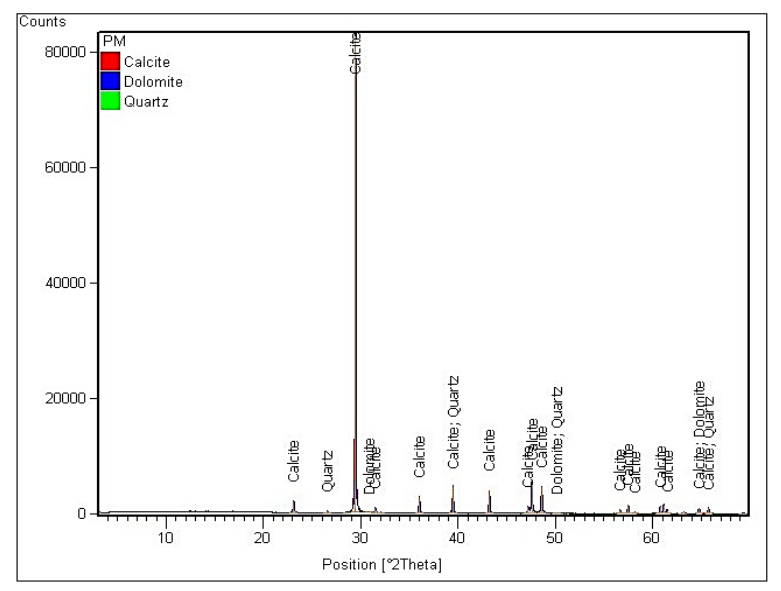

Figure 3. Diffractometer analysis X-ray of marble powder

\subsection{Experimental program}

The experimental program consists of two mini parts:

The first part: A series of mortars were formed by partial substitution of the dune sand by the marble powder with the percentages $(5,10,15,20,25$, and 30$) \%$, the porosity curve of the mixture sand dune-marble powder represented on the Figure 4 show that the minimum porosity is in the range of $(10$, 20) $\%$.

The second part: the geometry and the surface state of the sand grains present a low friction between a grains and a rather weak cohesion between the grains and the cement paste, a second mixture of sands is made by partial substitution of dune sand by crushed marble sand of angular geometry and better surface roughness with percentages of $(20,40,50,60,80) \%$ 
to improve the friction and cohesion. The porosity curve of the mixtures is plotted (Figure 5). The minimum porosity is obtained for the mixture $20 \%$ of crushed marble sand and $80 \%$ of dune sand, to maintain an acceptable porosity a second partial substitution of the mixed sand by the marble powder is made with the percentages of $(5,10,15,20,25,30) \%$. The porosity curve (Figure 4) shows that the minimum porosity is obtained around $15 \%$ substitutions. A series of mortar is made with the mixture of $(20,80$ and 15$) \%$ crushed marble sand, dune sand and marble powder respectively with dosages of $1 \%$ and $2 \%$ of superplasticizer Medaplast sp 40 as shown on the Table 2.

Control mortar is made without admixture and without marble powder. Calculation method of mortar mixture composition is applied in accordance with the Russian absolute volume (method of Scramtaïv) without air entrained [33]. The Mortars tests were carried out for the constant cement / sand (C / S) ratio of 0.9 .

Table 2. Denomination of mortars based on dune sand and mixed sand with admixture percentage

\begin{tabular}{ccc}
\hline Désignation & Marble powder (\%) & Admixture (\%) \\
\hline $\mathrm{M}_{1}$ & 0 & - \\
$\mathrm{M}_{2}$ & 10 & - \\
$\mathrm{M}_{3}$ & 15 & - \\
$\mathrm{M}_{4}$ & 20 & - \\
$\mathrm{Mms}_{1}$ & - & 0 \\
$\mathrm{Mms}_{2}$ & - & 1 \\
$\mathrm{Mms}_{3}$ & - & 2 \\
\hline
\end{tabular}

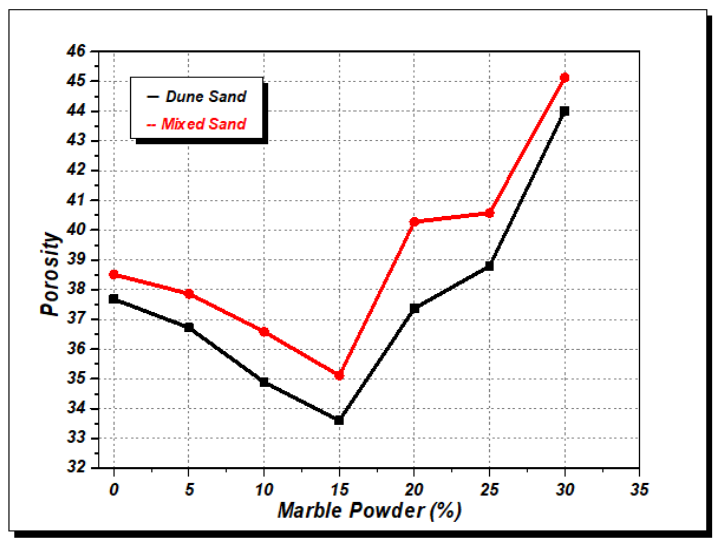

Figure 4. Porosity of dune sand and mixed sand with marble powder

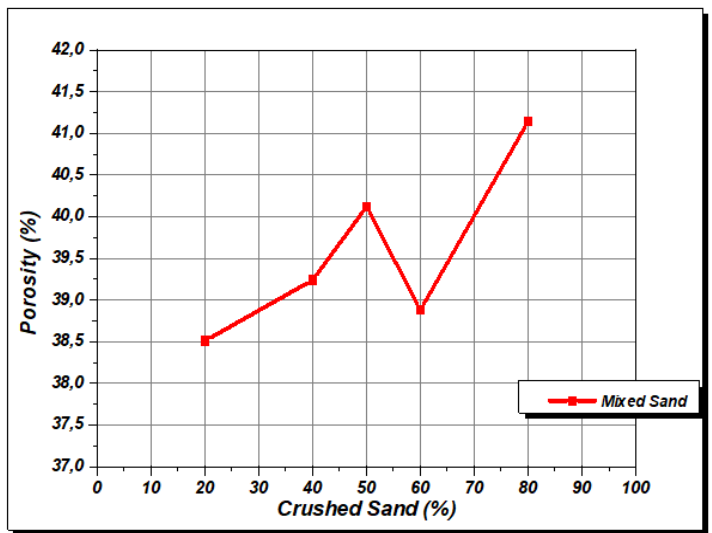

Figure 5. Porosity of mixed sand with percentage of crushed sand
Mechanical response: The mortar specimens of $4 \mathrm{~cm} \times 4 \mathrm{~cm}$ $\mathrm{x} 16 \mathrm{~cm}$ were subjected to mechanical strength tests at 7,14 and 28 days. After casting, the specimens were coated with plastic sheets at $20^{\circ} \mathrm{C}$ for $24 \mathrm{~h}$. After $24 \mathrm{~h}$, the test pieces were demolded and stored in water at $20^{\circ} \mathrm{C}$ until the age of test. The results reported in this work are the mean of three values obtained.

Water absorption by immersion $(A b)$ : water absorption was determined from the decrease in weight of three mortars prismatic specimens of $7 \mathrm{~cm} \times 7 \mathrm{~cm} \times 14 \mathrm{~cm}$ size, from each mixture saturated by water and then dried at $105^{\circ} \mathrm{C}$ to constant weight in accordance with ASTM C 642-97 [34]. The results are expressed in weight percent (wt \%).

$$
\mathrm{Ab}(\%)=\left[\left(\mathrm{W}_{\mathrm{W}}-\mathrm{W}_{\mathrm{D}}\right) / \mathrm{W}_{\mathrm{D}}\right] \times 100
$$

whence:

$\mathrm{W}_{\mathrm{w}}$ : wet weight;

$\mathrm{W}_{\mathrm{d}}$ : dry weight.

\section{RESULTS AND DISCUSSION}

\subsection{Mortar based on dune sand}

The optimal design granular skeleton was chosen by adding the marble powder with different percentages $(5,10,15,20$, 25 , and 30 ) to the dune sand; this allowed us to determine the minimum porosity of the mixture as shown in Figure 4 . The optimal mixtures selected for study (in terms of minimum porosity) are shown in Table 1 . The analysis of the results is done in the fresh and hardened state of the mortar.

\subsubsection{Fresh state}

The fluidity of the cement matrix is kept more acceptable range. It can be seen in Figure 6, that the addition of marble powder with increasing rates $(0 \%, 10 \%, 15 \%$ and $20 \%)$ leads to an increase in the ratio $\mathrm{W} / \mathrm{C}$ despite the incorporation of a water reducing agent, this is mainly due to the fineness of the cement $\left(\mathrm{SSB}=4000-5200 \mathrm{~cm}^{3} / \mathrm{g}\right.$ ) and the marble powder $\left(\mathrm{SSB}=2731 \mathrm{~cm}^{3} / \mathrm{g}\right)$ which is important which increases the demand for water. It is noted that the incorporation a super plasticizer at dosages of $1 \%$ and $2 \%$ in the presence of marble powder has reduced by more than $14 \%$ the $\mathrm{W} / \mathrm{C}$ ratio, which is explained by the lubrication of the grains which leads to a lowering of the cohesion force between grains leading to a better flowing behavior of the cement matrix.

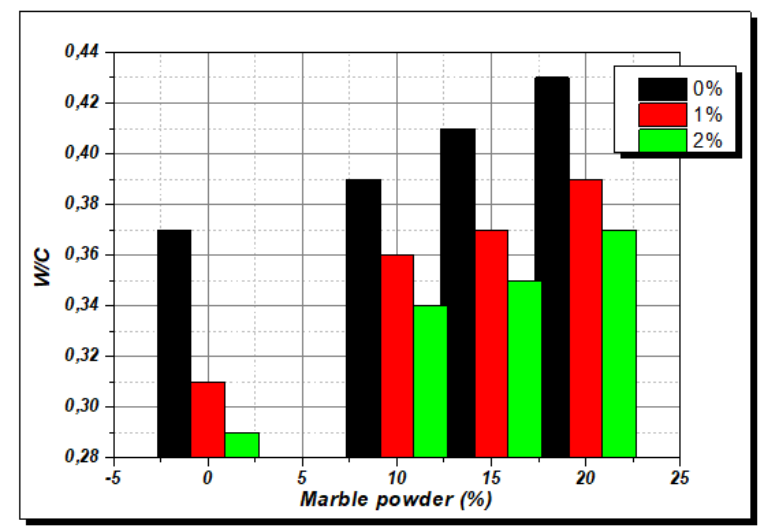

Figure 6. Variation of water cement ratio for various percentages of marble powder 
The present results obtained are in accordance with research work undertake Kore and Vyas [35].

\subsubsection{Hardened state}

Water absorption by immersion: Figure 7 shows that the addition of marble powder has a significant influence on the absorption capacity factor indicating the degree of clamping (rearrangement of grains). It is found that the addition of the marble powder for the mortar without admixture is caused by a decrease in the absorption capacity. $15 \%$ addition of marble powder leads to the minimum absorption capacity, beyond $15 \%$ addition the absorption capacity shows an increase, this is mainly due to the variation of the porosity as shown by the Figure 4. The effect of the incorporation of the admixture (lubricant) improves the clamping mode of the grains it is clearly visible for $0 \%, 10 \%$ and $20 \%$ addition of marble powder because the mortar still has a fairly high porosity, at $15 \%$ addition of marble powder the minimum porosity is reached the rearrangement of grains by lubrication is already achieved.

In effect, the marble powder adsorbs more water than cement. As a result, the ratio of water available for hydration is reduced leading to better compactness of the mortar. Similar research has been found by Talah et al. [36] and Ashish et al. [37], in which explain the role of marble powder fineness that reduces the pore size distribution compared to control mortar.

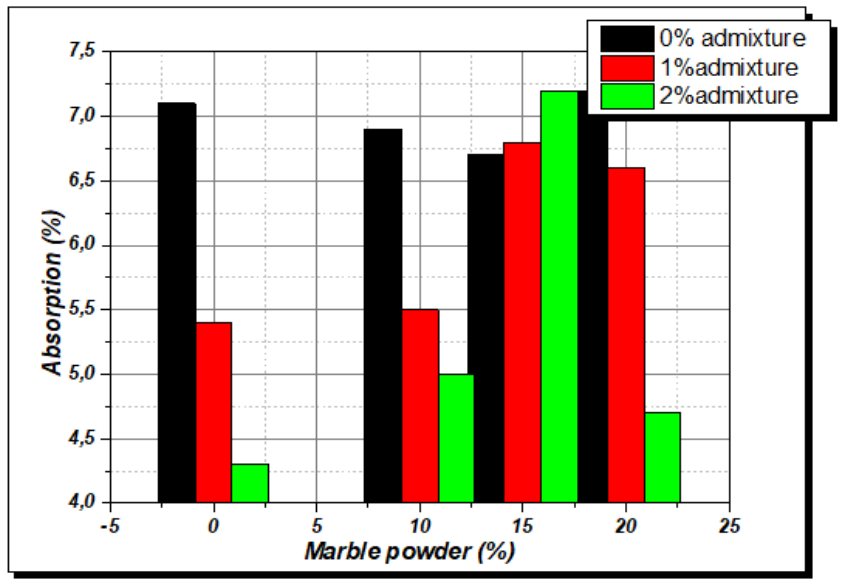

Figure 7. Absorption capacity versus percentage of marble powder

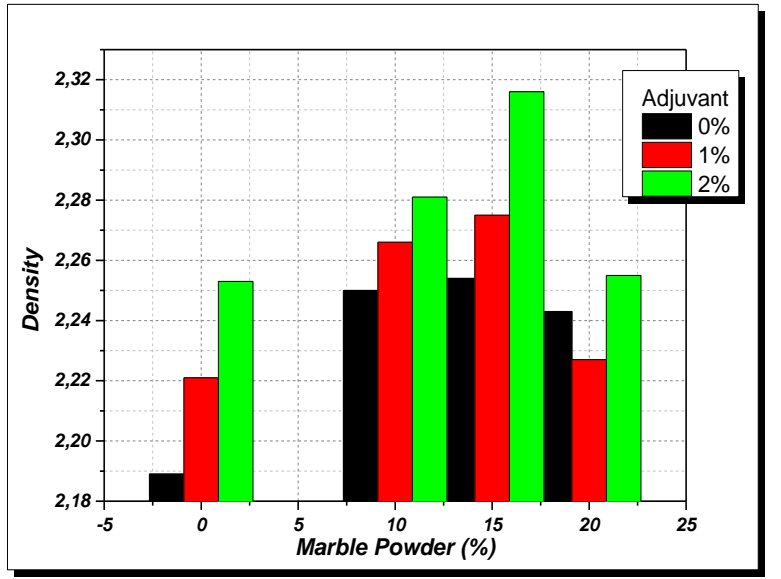

Figure 8. Density variation versus added marble powder for studied mortars
Density: Figure 8 shows an increase in the density by increasing the percentage of marble powder in the cementitious matrix with or without admixture, for a $15 \%$ addition the density reaches an optimum value of $2.316 \mathrm{~kg} / 1$. We note that the addition of $20 \%$ of marble powder causes a decrease in the density despite the use of the admixture; this is essentially due to the increase in the porosity of dune sand with marble powder as shown in Figure 4. It should be noted that the introduction of the super plasticizer leads to an increase in the density, this is essentially due to the lubrication of the cement matrix particles and the optimization of the clamping mode.

The highest density with and without admixture appears up to $15 \%$ of marble powder specimen, especially at early curing ages, this result in agreement with [38, 39].

Mechanical strengths: The gradual addition of the marble powder in the cement matrix to a threshold of $15 \%$ free of admixture improves the mechanical strengths. For mortars without admixture, the compressive and flexural strengths are improved by more than $9 \%$ and $7 \%$, respectively, which are well shown in Figure 9 and Figure 10; this is mainly due to the reduction of the porosity of the mixture (dune sand with marble powder) which is illustrated on Figure 7. The combination of the marble powder with the MEDA PLAST SP 40 admixture allows a greater improvement of the mechanical compressive and flexural strengths as shown in Figure 9 and Figure 10. For example, the combined addition of $15 \%$ of marble powder and $2 \%$ of admixture (MEDAPLAST SP 40) gives an improvement in compressive and flexural strengths exceeding $20 \%$ and $14 \%$ respectively at 28 days of cure, an optimum of $74.49 \mathrm{MPa}$ for compressive strength and 12.52 $\mathrm{MPa}$ for flexural strength are noted, this is mainly due to the decrease in the porosity of the dune sand mixture with $15 \%$ of marble powder as shown in Figure 4 and the lowering of the cohesion force between grains by lubrication which facilitates a better mode of grain tightening (better compactness). At $20 \%$ of marble powder combined with $1 \%$ and $2 \%$ of admixture, the compressive and flexural strengths still remain superior to those of the control mortar. This is development in compressive strength up to $15 \%$ MP may be related to the chemical and physical effect of marble powder. The strength of mix is decreased due to decrease in cementing materials tricalcium silicate $\left(\mathrm{C}_{3} \mathrm{~S}\right)$ and dicalcium silicate $\left(\mathrm{C}_{2} \mathrm{~S}\right)$ [37].

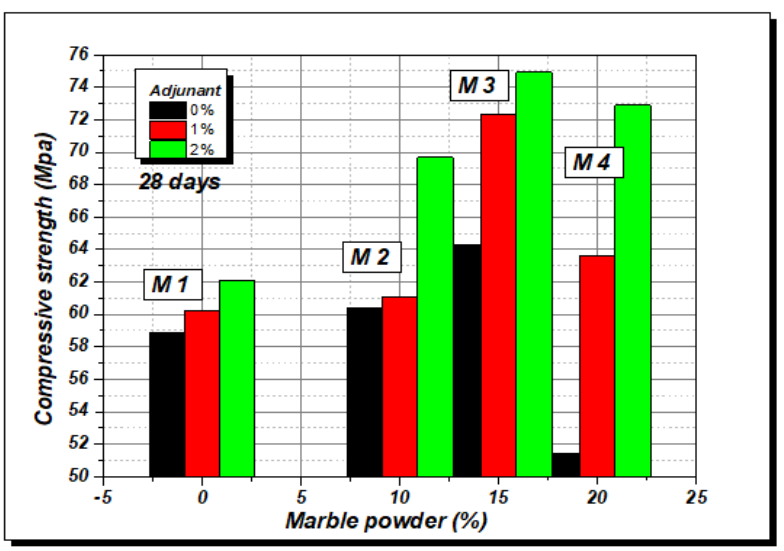

Figure 9. Variation in compressive strength versus of marble powder dosages for studied mortars

It can be concluded that, the recycling of $15 \%$ of marble waste in the form of powder in the cement matrix has no negative effect on the mechanical properties of the mortar, but 
in the short run we have achieved better mortar performance and preserve environment from these harmful wastes. The valorization of the marble powder combined with a waterreducing admixture in the making of the mortar is a very good alternative of the recycling of the marble waste. These results are in agreement with those concluded by Ashish et al. [37].

\subsection{Mortar with mixed sand}

The dune siliceous sand is composed of grains of spherical geometry with a smooth surface state, the cohesive force between grains and between grains and cement paste is lowest, so the addition of crushed marble sand composed of grains of angular geometry with a rough surface state makes it possible to increase the cohesion strength between grains and cement paste and corrected the particle size of the dune sand as shown in Figure 2.

In order to maintain the minimal porosity of the dune sand with $15 \%$ more or less constant marble powder, mixed sand is made by adding $20 \%$ of crushed marble sand, as shown in Figure 4. Discussion of the results at the fresh and hardened state of the mortar made with mixed sand is done as follows.

\subsubsection{Fresh state}

The angular geometry and grain roughness of crushed marble sand partially substituting dune sand allows for an improvement of the granular skeleton of dune sand as shown in Figure 4 and to increase the cohesive strength between grains of the mixed sand, but this substitution is not without effect, the mixing water increases to maintain the required fluidity. A superplasticizer is introduced at rate of $1 \%$ and $2 \%$ by weight of cement. Analysis of the water reduction and W/ $\mathrm{C}$ ratio of the fresh mortar is necessary.

Figure 10, shows that the addition of $15 \%$ of marble powder in the cement matrix increases the amount of mortar mixing water by more than $10 \%$ and the substitution of $20 \%$ of dune sand by crushed marble sand generates an increase in the amount of mixing water of more than $16 \%$, this is mainly due to the presence of a large amount of fine (marble powder and cement) and to the increase of the cohesive force generated by the particle geometry of the crushed marble sand which increases the amount of water mixing to maintain a constant fluidity. The introduction of the superplasticizer with $1 \%$ and $2 \%$ to reduce superfluous water by more than $22 \%$ for the control mortar and by more than $17 \%, 22 \%$ for the mortar based on dune sand and for those based on mixed sand, respectively.

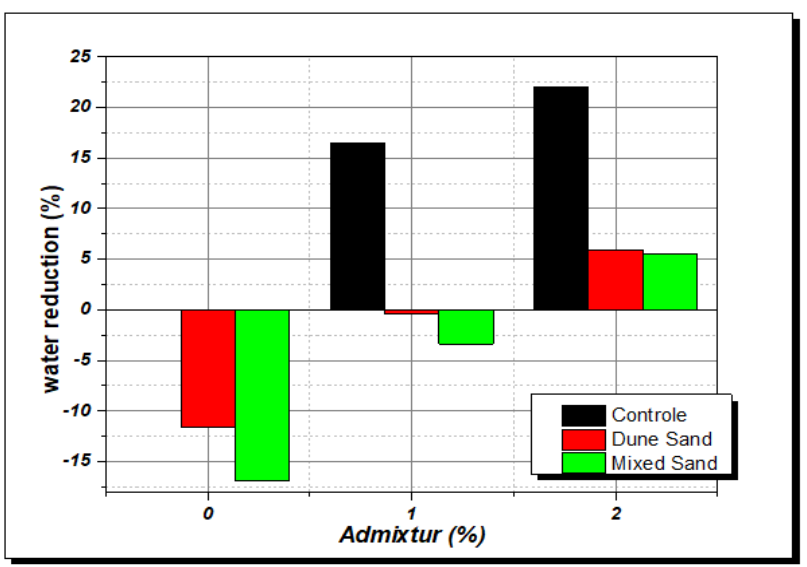

Figure 10. Mixed water reduction according on the admixture percentage for studied mortars
Figure 11, shows that the addition of $15 \%$ of marble powder and the $20 \%$ substitution of dune sand by crushed marble sand results in a higher $\mathrm{W} / \mathrm{C}$ ratio for mortars with dune sand or mixed sand with or without admixture, the introduction of $1 \%$, $2 \%$ of admixture reduces the $\mathrm{W} / \mathrm{C}$ ratio from 0.43 to 0.35 for the mortar based on mixed sand, from 0.41 to 0.35 for the mortar based on dune sand, from 0.37 to 0.29 for the control mortar. This is mainly due to the lubrication power that allows the best clamping mode. On the other hand, the difference between the water-cement ratio of various mortars tested, depends of the content of the crushed fine aggregates (crushed marble) incorporated in the natural fine aggregate (difference of the density and the porosity between the different fine aggregates studied [40].

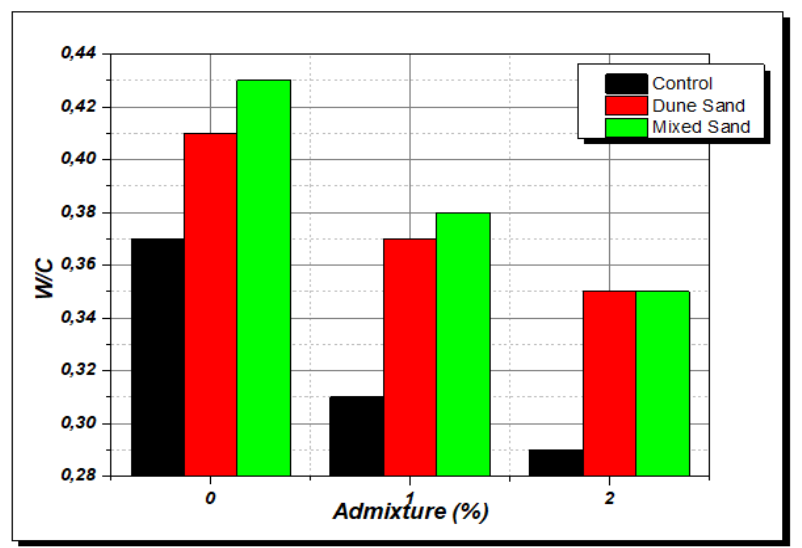

Figure 11. W / C ratio according to the admixture percentage for studied mortars

\subsubsection{Hardened state}

Among the essential parameters emphasizing the performance of the mortar in the cured state are the density and the mechanical strength.

Density: Figure 12, shows an increase in density of mortar with dune sand or with mixed sand with or without admixture, this is mainly due to the reinforcement of the granular skeleton by adding marble powder and by partial substitution of sand dune by crushed marble sand which has led to a minimum porosity shown in Figure 4 and a better compactness. It is noted that the addition of the super plasticizer is followed by an increase in the density.

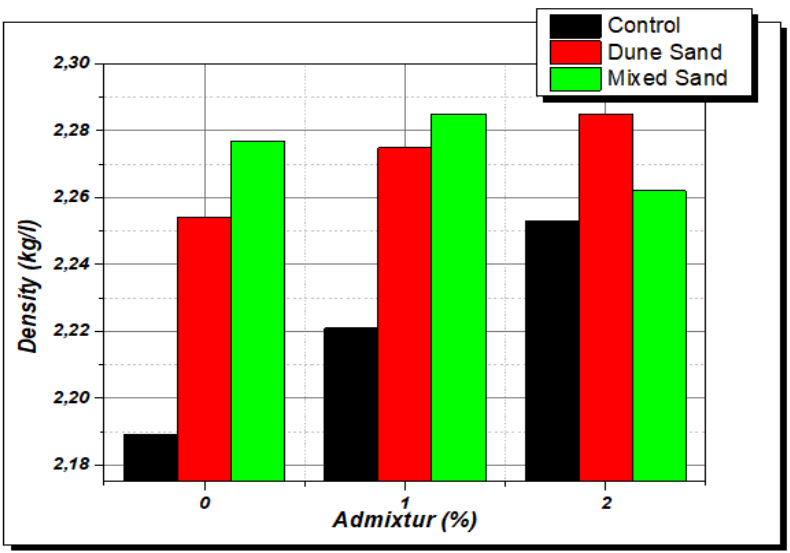

Figure 12. Density as a function of admixture for the different mortars

Figure 13, shows that the addition of the marble powder 
gives rise to a fairly high absorption with or without admixture, this is essentially due to the presence of a large amount of fine (cement + marble powder) in the cement matrix. The combined effect of the addition of super plasticizer and the partial substitution of dune sand by crushed marble sand reduces water absorption, due to the reduction of marble powder in the cement matrix.

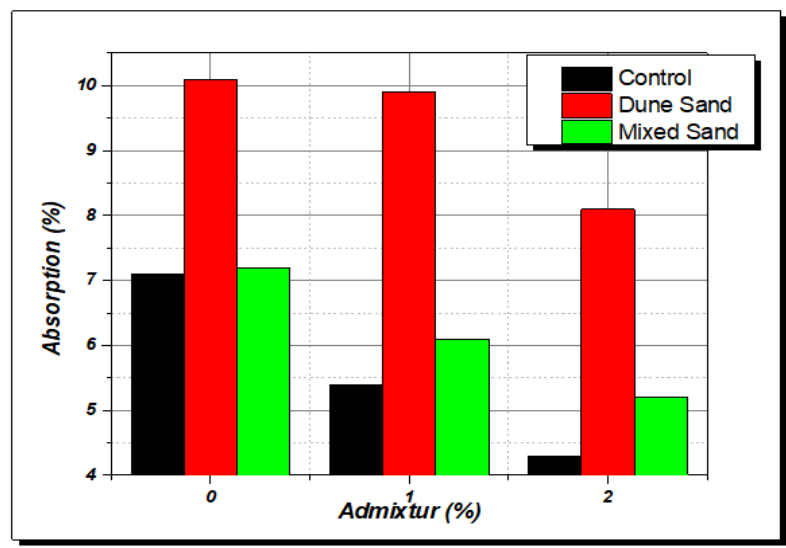

Figure 13. Absorption coefficient with admixture the different mortars

The mechanical strengths: Figure 14, shows that the addition of the marble powder to the cementitious matrix causes an increase in compressive strength, especially if this addition is accompanied by the incorporation of a super plasticizer, at $2 \%$ addition of superplasticizer, the compressive strength of sand-based mortar containing $15 \%$ marble powder at a young age (14 days) reaches a peak of $74.61 \mathrm{MPa}$. It is noted an improvement in compressive strength exceeding $60 \%$.

The partial substitution of $(20 \%)$ dune sand by crushed marble sand always shows an improvement in compressive strength compared to the control mortar, the compressive strength at 14 day of the mixed sand mortar with $1 \%$ superplasticizer added is significantly improved, but it always remains inferior to that of the sand dune mortar, but it always remains inferior to that of the mortar based on dune sand, this is due to the lack of lubrication of its particles which leads to a lower clamping. The addition of $2 \%$ of superplasticizer allows a better lubrication of the particles and the cohesion force between particles is reduced, the tightening mode is better which makes it possible to reach and exceed compressive strengths of $75 \mathrm{MPa}$.

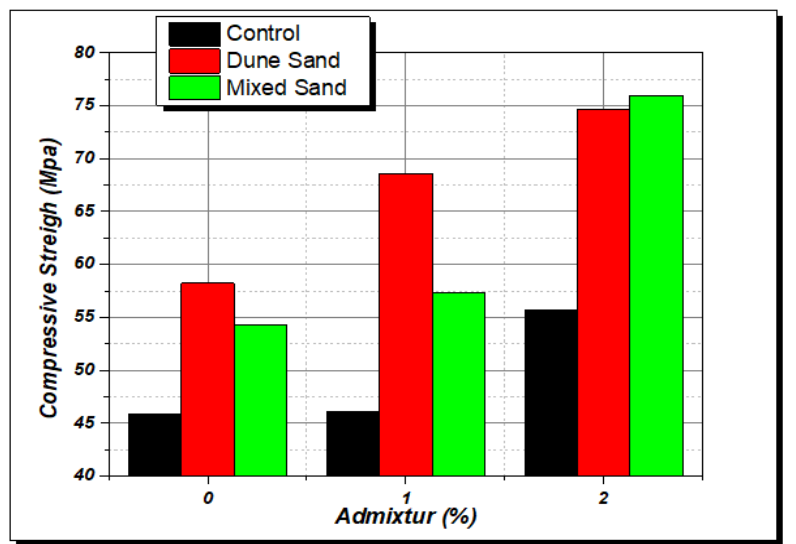

Figure 14. Compressive strength as a function of the admixture percentage for studied mortars
Figure 15, shows that the addition of the marble powder in the cementitious matrix with or without admixture allows a notable improvement of the flexural strength, this improvement is $25 \%$ higher than that of the control mortar, this is essentially down to the porosity of dune sand with $15 \%$ marble powder shown in Figure 7, example, the 14-day bending strength of the sand dune mortar with $15 \%$ marble powder and $2 \%$ additive reaches a value of $11.62 \mathrm{MPa}$. The partial substitution of $20 \%$ of dune sand by crushed marble sand shows better performance with or without additives, this is due mainly to the increase in the cohesion force between grains generated by the geometric shape (angular shape) of the particles of the crushed marble sand. The introduction of the superplasticizer with a dosage of $1 \%$ and $2 \%$ by weight of cement in the cement matrix resulted in resistance peaks, at 14 days age with $2 \%$ super plasticizer flexural strength reaches a peak of $12.89 \mathrm{MPa}$. There is also a significant improvement in the essential mechanical characteristics of the mortars studied. The improvement of results was due to good strength and low porosity of both the interfacial transition zone (ITZ) and cement paste matrix. Similar results were achieved by Rana et al. [41] and Ashish et al. [37].

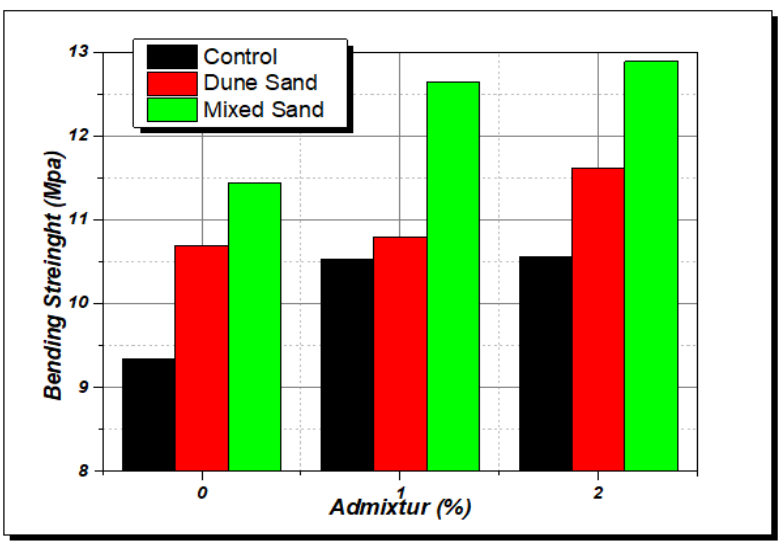

Figure 15. Flexural strength as a function of admixture percentage for studied mortars

Finally, we note that the use of $15 \%$ of powdered marble waste and the substitution of sand dune by $20 \%$ of crushed marble sand (marble waste) allowed us to recycle $35 \%$ of this waste and to contribute to preserve the environment.

\section{CONCLUSIONS}

This present research allowed us to carry out a comparative study between a control mortar without additions and a mortar at a varied rate of addition of marble powder to sand dune used until a minimum porosity. In first step, let's introduce an admixture at different percentages. The second step is to make a mortar with dune sand with marble powder to which is added crushed marble sand and an adjuvant with different percentages the mechanical characteristics of the mixed sand mortar and control mortar were compared.

\section{$\checkmark$ The results of sand dune mortars showed that:}

The fluidity: The incorporation a super plasticizer at dosages of $1 \%$ and $2 \%$ in the presence of marble powder - increasing rates $(0 \%, 10 \%, 15 \%$ and $20 \%)$ - has reduced by more than $14 \%$ the $\mathrm{W} / \mathrm{C}$ ratio, which is explained by the lubrication of the grains which leads to a lowering of the cohesion force 
between grains leading to a better flowing behavior of the cement matrix;

Water absorption by immersion: The addition of 15\% of marble powder leads to the minimum absorption capacity and beyond $15 \%$ addition the absorption capacity increases;

Density: The highest density with and without admixture appears up to $15 \%$ of marble powder specimen, especially at early curing ages.

\section{Mechanical strengths:}

- The gradual addition of the marble powder in the cement matrix to a threshold of $15 \%$ without admixture improves the mechanical strengths. The compressive and flexural strengths are improved by more than $9 \%$ and $7 \%$, respectively;

- The combination of the marble powder with the admixture allows a greater improvement of the mechanical compressive and flexural strengths. The combined addition of $15 \%$ of marble powder and $2 \%$ of admixture gives an improvement in compressive and flexural strengths exceeding $20 \%$ and $14 \%$ respectively at 28 days of cure;

- The recycling of $15 \%$ of marble waste in the form of powder in the cement matrix has no negative effect on the mechanical properties of the mortar.

$\checkmark$ On the other hand, the results of mortar with mixed sand showed that:

Fluidity: the addition of $15 \%$ of marble powder in the cement matrix increases the amount of mortar mixing water by more than $10 \%$ and the substitution of $20 \%$ of dune sand by crushed marble sand generates an increase in the amount of mixing water of more than $16 \%$. The introduction of the superplasticizer with $1 \%$ and $2 \%$ to reduce superfluous water by more than $22 \%$ for the control mortar and by more than $17 \%, 22 \%$ for the mortar based on dune sand and for those based on mixed sand, respectively.

Density: The combined effect of the addition of super plasticizer and the partial substitution of dune sand by crushed marble sand reduces water absorption, due to the reduction of marble powder in the cement matrix;

Mechanical strengths: The partial substitution of $20 \%$ of dune sand by crushed marble sand shows better performance with or without additives. The compressive and flexural strength peaks exceeding $74 \mathrm{MPa}$ and $12 \mathrm{MPa}$, respectively at early age.

Finally, the results of this study can be summarized in the following points:

For the mortar based on dune sand, the addition of the marble powder allowed the reduction of the porosity of the sand a marked improvement of the compressive and flexural strengths. The combined addition of the marble powder and the superplasticizer allows a significant reduction in the amount of mixing water and achieving compressive and flexural strength peaks exceeding $74 \mathrm{MPa}$ and $12 \mathrm{MPa}$, respectively.

For mixed sand mortar, the addition of crushed marble sand corrects the granularity of dune sand, increases cohesion between grains, reduces the amount of mixing water and achieves better strength results.

Finally, the use of $35 \%$ of marble waste in the form of powder and crushed sand has significantly improved the mechanical properties of the mortar. Further, a reduction the amount of marble waste by recycling and this contributed to the preservation of the environment.
Through this study, we suggest future works in this field, which are represented in: replacement of crushed marble sand by crushed glass sand; replacement of marble powder by fine dune sand.

\section{ACKNOWLEDGMENT}

The authors would like to express their acknowledgement for the help, support and encouragements that were provided by all those people who contributed to the preparation of the present work.

\section{REFERENCES}

[1] Faiz, Z., Fakhi, S., Bouih, A., Idrissi, A., Mouldouira, M. (2012). Radioactive waste management: optimization of the mechanical property of cemented Ion Exchange Resin. Journal of Materials and Environmental Science, 3(6): 1129-1136.

[2] Kherbache, S., Bouzidi, N., Bouzidi, M.A., Moussaceb, K., Tahakourt, A.K. (2016). The behavior of the concretes and mortars reinforced by metallic fibers wastes as substitution of cement. Journal of Materials and Environmental Science, 7(1): 18-29.

[3] Handel, N., Hafsi, B., Touati, A., Djabbar, Y. (2011). Substitution of the aggregate by solid waste of blast furnance in the preparation of concrete. Journal of Materials in Environmental Sciences, 2: 520-525.

[4] Chaid, R., Jauberthie, R., Zeghiche, J., Kherchi, F. (2011). Impact de la poudre de marbre conjuguée au calcaire du CEM II sur la durabilité du béton. European Journal of Environmental and Civil Engineering, 15(3): 427-445. https://doi.org/10.1080/19648189.2011.9693335

[5] Senhadji, Y., Escadeillas, G., Mouli, M., Khelafi, H. (2014). Influence of natural pozzolan, silica fume and limestone fine on strength, acid resistance and microstructure of mortar. Powder Technology, 254: 314323. https://doi.org/10.1016/j.powtec.2014.01.046

[6] Marchal, G. (2002). L'efficacité écologique des ciments mélangés: Tendances et possibilités d'une approche écologique. ECOTRADE, Italie.

[7] Petkovic, G., Engelsen, C.J., Håøya, A.O., Breedveld, G. (2004). Environmental impact from the use of recycled materials in road construction: method for decisionmaking in Norway. Resources, Conservation and Recycling, $\quad 42(3)$ : https://doi.org/10.1016/j.resconrec.2004.04.004

[8] Levy, S.M., Helene, P. (2004). Durability of recycled aggregates concrete: A safe way to sustainable development. Cement and Concrete Research, 34(11): 1975-1980. https://doi.org/10.1016/j.cemconres.2004.02.009

[9] Oikonomou, N.D. (2005). Recycled concrete aggregates. Cement and Concrete Composites, 27(2): 315-318. https://doi.org/10.1016/j.cemconcomp.2004.02.020

[10] Sadek, D.M., El-Attar, M.M., Ali, H.A. (2016). Reusing of marble and granite powders in self-compacting concrete for sustainable development. Journal of Cleaner Production, 121: 19-32. https://doi.org/10.1016/j.jclepro.2016.02.044

[11] Saidani, K., Ajam, L., Ouezdou, M.B. (2015). Barite 
powder as sand substitution in concrete: Effect on some mechanical properties. Construction and Building Materials, $\quad 95(1)$ : 287-295. https://doi.org/10.1016/j.conbuildmat.2015.07.140

[12] Unčík, S., Kmecová, V. (2013). The effect of basalt powder on the properties of cement composites. Procedia Engineering, 65: 51-56 https://doi.org/10.1016/j.proeng.2013.09.010

[13] Szaj, P. (2014). Stone meal as a addition to concrete. Mining Science, 21(1): 215-226.

[14] Sood, V., Singh, L.P., Diwedi, A., Agarwal, S.K. (2012). Effect of admixture on the compressive strength of composite cement mortar. Concrete Research Letters, 3: 541-549. https://doi.org/10.1007/s12205-011-0962-x

[15] Uysal, M., Akyuncu, V., Tanyildizi, H., Sumer, M., Yildirim, H. (2018). Optimization of durability properties of concrete containing fly ash using Taguchi's approach and Anova analysis. Revista De La Construcción, Journal of Construction, 17(3): 364-382. https://doi.org/10.7764/RDLC.17.3.364

[16] Uysal, M., Yilmaz, K. (2011). Effect of mineral admixtures on properties of self-compacting concrete. Cement and Concrete Composites, 33(7): 771-776. https://doi.org/10.1016/j.cemconcomp.2011.04.005

[17] Tikkanen, J., Penttala, V., Cwirzen, A. (2011). Mineral powder concrete-effects of powder content on concrete properties. Magazine of Concrete Research, 63(12): 893903. https://doi.org/10.1680/macr.10.00048

[18] Çakır, Ö., Sofyanlı, Ö.Ö. (2015). Influence of silica fume on mechanical and physical properties of recycled aggregate concrete. HBRC Journal, 11(2): 157-166. https://doi.org/10.1016/j.hbrcj.2014.06.002

[19] Rauf, N., Hasruddin, M. (2012). The influence of fly ash and shell-fish on physical property of concrete cement. In AIP Conference Proceedings, 1454(1): 272-274. https://doi.org/10.1063/1.4730738

[20] Vejmelková, E., Kotátková, J., Čáchová, M., Koňáková, D. (2016). Comparison of the effects of different pozzolana on the properties of self-compacting concrete. In Key Engineering Materials, 677: 103-107. https://doi.org/10.4028/www.scientific.net/KEM.677.10 3

[21] Kavas, T., Olgun, A. (2008). Properties of cement and mortar incorporating marble dust and crushed brick. Ceramics Silikaty, 52(1): 24

[22] Awad, A.H., Abdel-Ghany, A.W., El-Wahab, A., Ayman, A., El-Gamasy, R., Abdellatif, M.H. (2020). The influence of adding marble and granite dust on the mechanical and physical properties of PP composites. Journal of Thermal Analysis and Calorimetry, 140(6): 2615-2623. https://doi.org/10.1007/s10973-019-09030W.

[23] Agarwal, S.K., Gulati, D. (2006). Utilization of industrial wastes and unprocessed micro-fillers for making cost effective mortars. Construction and Building Materials, 20(10): 999-1004. https://doi.org/10.1016/j.conbuildmat.2005.06.009

[24] Mansour, R., El Abidine, R.Z., Brahim, B. (2017). Performance of polymer concrete incorporating waste marble and alfa fibers. Advances in Concrete Construction, 5(4): 331-343 https://doi.org/10.12989/acc.2017.5.4.331

[25] Ouassila, B., Houria, H., Leila, K., Mouloud, B., Assia, A., Chaher, R. (2020). Valorization of marble's waste as a substitute in sand concrete. Advances in Concrete Construction, $9(2)$ : 217-225. https://doi.org/10.12989/acc.2020.9.2.217

[26] Yamanel, K., Durak, U., İlkentapar, S., Atabey, İ.İ., Karahan, O., Duran, C. (2019). Influence of waste marble powder as a replacement of cement on the properties of mortar. Journal of Construction, 18(2): 290-300. http://dx.doi.org/10.7764/rdlc.18.2.290

[27] Kabeer, K.S.A., Vyas, A.K. (2018). Utilization of marble powder as fine aggregate in mortar mixes. Construction and Building Materials, 165: 321-332. https://doi.org/10.1016/j.conbuildmat.2018.01.061

[28] Alyamaç, K.E., Aydin, A.B. (2015). Concrete properties containing fine aggregate marble powder. KSCE Journal of Civil Engineering, 19(7): 2208-2216. https://doi.org/10.1007/s12205-015-0327-y

[29] Zhang, J., Cai, D.S., Wang, T.K., Hu, Q., Kengming, L.I. (2018). Experimental analysis on the effects of artificial marble waste powder on concrete performance. Annales de Chimie. Science des Materiaux, 42(3): 347-362. https://doi.org/10.3166/ACSM.42.347-362

[30] Belouadah, M., Rahmouni, Z.E.A., Tebbal, N. (2019). Influence of the addition of glass powder and marble powder on the physical and mechanical behavior of composite cement. Procedia Computer Science, 158: 366-375. https://doi.org/10.1016/j.procs.2019.09.064

[31] Belouadah, M., Rahmouni, Z.E., Tebbal, N., Hicham, M.E.H. (2021). Evaluation of concretes made with marble waste using destructive and non-destructive testing. Annales de Chimie-Science des Matériaux, 45(5): 361-368. https://doi.org/10.18280/acsm.450501

[32] NF EN 933-1. (2006). Essais Pour Déterminer les Caractéristiques Géométriques des Granulats-Partie 1: Détermination de la granularité-analyse granulométrique par tamisage.

[33] Komar, A. (1978). Matériaux et éléments de construction, Edit. Mir, Moscou, Russie, 539.

[34] ASTM C 642-97. (1997). Standard test method for density, absorption, and voids in hardened concrete. American Society for Testing and Materials, USA

[35] Kore, S.D., Vyas, A.K. (2016). Impact of marble waste as coarse aggregate on properties of lean cement concrete. Case Studies in Construction Materials, 4: 85-92. https://doi.org/10.1016/j.cscm.2016.01.002

[36] Talah, A., Kharchi, F., Chaid, R. (2015) Influence of marble powder on high performance concrete behavior. Procedia Engineering, 114: 685-690. https://doi.org/10.1016/j.proeng.2015.08.010

[37] Ashish, D.K., Verma, S.K., Kumar, R., Sharma, N. (2016). Properties of concrete incorporating sand and cement with waste marble powder. Advances in Concrete Construction, 4(2): 145-160. https://doi.org/10.12989/acc.2016.4.2.145

[38] Mohamadien, H.A. (2012). The effect of marble powder and silica fume as partial replacement for cement on mortar. International Journal of Civil and Structural Engineering, $\quad 3(2)$ : 418-428. https://doi.org/10.6088/ijcser.201203013039

[39] Latha, G., Suchith Reddy, A., Mounika, K. (2015). Experimental investigation on strength characteristics of concrete using waste marble powder as cementitious material. International Journal of Innovative Research in Science, Engineering and Technology, 4(12): 1269112698. https://doi.org/10.15680/IJIRSET.2015.0412070 
[40] Maza, M., Naceri, A., Zitouni, S. (2016). Physicomechanical properties of mortar made with binary natural fine aggregates (dune sand and crushed sand) with and without chemical admixture. Asian Journal of Civil Engineering (BHRC), 17(5): 663-682.

[41] Rana, A., Kalla, P., Csetenyi, L.J. (2015). Sustainable use of marble slurry in concrete. Journal of Cleaner Production, 94:

https://doi.org/10.1016/j.jclepro.2015.01.053

\section{NOMENCLATURE}

CEM II/A Portland cement type MP Marble Powder
$\mathrm{W} / \mathrm{C}$
Water Cement Ratio

wet weight

dry weight

Water absorption by immersion

dune sand

Control mortar

mortar with $10 \% \mathrm{MP}$ and $0 \%$ admixture mortar with $15 \% \mathrm{MP}$ and $0 \%$ admixture mortar with $20 \% \mathrm{MP}$ and $0 \%$ admixture mortar with $0 \% \mathrm{MP}$ and $0 \%$ admixture mortar with $0 \% \mathrm{MP}$ and $1 \%$ admixture mortar with $0 \% \mathrm{MP}$ and $2 \%$ admixture European Committee for Standarization American Society for Testing and Materials 